\title{
ВЛИЯНИЕ ВЕРБАЛЬНОГО ИНТЕЛЛЕКТА И ПСИХОЛОГИЧЕСКИХ ОСОБЕННОСТЕЙ ЛИЧНОСТИ НА ПОВЕДЕНИЕ В КОНФЛИКТЕ УЧАСТНИКОВ ИНТЕРНЕТ-ФОРУМОВ
}

\section{THE IMPACT OF VERBAL INTELLIGENCE AND PERSONAL PSYCHOLOGICAL SINGULARITIES ON THE CONFLICT BEHAVIOUR OF INTERNET FORUM USERS \\ Iu. Astrakhantseva \\ A. Varnin \\ M. Glavatskikh}

Summary: The increase of conflicts in virtual environment and it's negative impact on personality has been noted by many authors. The aim of the study was to identify and analyze the psychological determinants of the types of reaction in the conflict of participants in Internet forums, namely, their psychological characteristics of personality and verbal intelligence. Research methods. To solve the tasks given, multiple regression analysis was applied with a step-by-step inclusion of the tested psychological indicators of personality and verbal intelligence of forum participants as variables of the regression model. Results. This study has proved the influence of Machiavellianism, general awareness on the subject and the ability to draw analogies with the ability to form complex intellectual models, which are necessary for making a constructive decision in a conflict. Conclusion. The results of this study make it possible to expand theoretical and empirical ideas about the state of psychological determinants of virtual communication.

Keywords: verbal intelligence, internet forum, conflict, virtual communication.
Астраханцева Юлия Львовна

к.псх.н., дочент, ФГБОУ ВО «Удмуртский государственный университет», г. Ижевск

Ulastra@mail.ru

Варнин Андрей Вячеславович

ФГБОУ ВО «Удмуртский государственный университет»,

г. Ижевск

abraham133@list.ru

Главатских Марианна Михайловна

к.nсх.н., дочент, ФГБОУ ВО «Удмуртский государственный университет», г. Ижевск ni-hao@mail.ru

Аннотация: Рост конфликтов в виртуальной среде и их отрицательное влияние на личность отмечается большинством авторов. Целью исследования явилось выявление и анализ психологических детерминант типов реагирования в конфликте участников интернет форумов, а именно их психологических особенностей личности и вербального интеллекта. Методы исследования. Для решения поставленных задач был применен множественный регрессионный анализ с пошаговым включением тестируемых психологических показателей личности и вербального интеллекта участников форумов в качестве переменных регрессионной модели. Результаты. Доказано влияние макиавеллизма, общей осведомленности и способности проводить аналогии с возможностями формировать сложные интеллектуальные модели, которые необходимы для принятия конструктивного решения в конфликте. Заключение. Результаты настоящего исследования позволяют расширить и конкретизировать теоретико-эмпирические представления о состоянии психологических детерминант виртуального общения.

Ключевые слова: вербальный интеллект, интернет-форум, конфликт, виртуальное общение.

задачей стоит изучение механизмов формирования деструктивной среды.

В работах отечественных и зарубежных ученых [Выготский Л.С., 2017, Черниговская Т.В., 2016, Колдуэлл-Харрис, 2019] показано, что базисные понятия языка влияют на перцептивное восприятие мира, а мышление сформировалось под воздействием культурно-исторической среды и предназначено для сборки интеллектуальных объектов разной степени сложности и новизны [Курпатов А.В. 2018]. Л. Витгенштейн пишет: «...границы моего языка - суть границы моего мира» [2, с.101]. Человек мыслит образами, язык «объективизирует» индивидуальные впечатления, обеспечивая познание социального мира и коммуникацию. Соответственно конфликтные ситуации, которые возникают в Интернете, тесно переплетены с личностью в целом. В качестве маркеров конфликт- 
ного поведения, опираясь на работы Доценко Е.Л. [5] и Шейнов В.П. [8], были выбраны такие психологические особенности как макиавеллизм, неклиническая психопатия, нарциссизм.

Цель исследования - изучить влияние вербального интеллекта и психологических особенностей личности на поведение в конфликте участников форумов. В исследовании приняли участие 46 респондентов - участники интернет-форумов, средний возраст которых составляет 29 лет, из них 23 мужчины и 23 женщины.

\section{Методы исследования}

В работе применялся психодиагностический метод, а именно методики исследования: опросник темной триады (в адаптации М.С. Егоровой, М.А. Ситниковой, О.В. Паршиковой), диагностирующий макиавеллизм, неклинический нарциссизм и неклиническую психопатию; опросник «диагностика ведущего типа реагирования» (М.М. Кашапов, Т.Г. Киселева), диагностирующий три вида реагирования в конфликте: агрессия, уход, решение; тест структуры интеллекта Амтхауэра, комплекс вербальных субтестов диагностирует общую способность оперировать словами, как сигналами и символами. Методом анкетирования выявлялось образование и частота общения на форумах. Количественные методы: проверка на нормальность распределения с применением критерия Колмогорова-Смирнова с поправкой значимости Лильефорса, критерий корреляции Спирмена и множественный регрессионный анализ методом пошагового включения.

\section{Результаты и их обсужление}

В ходе исследования для подготовки к проведению регрессионного анализа устанавливалась и описывалась взаимосвязь изучаемых показателей. В результате регрессионного анализа, где зависимой переменной выступал тип реагирования «агрессия», а предикторами психологические особенности личности и вербальный интеллект участников форума, выявлено влияние уровня образования и общей осведомленности (таблица 1).

Таблица 1.

Результаты исследования влияния вербального интеллекта, психологических особенностей личности и уровня образования на тип реагирования «Агрессия» участников форумов методом регрессионного многофакторного анализа.

\begin{tabular}{|l|c|c|c|}
\multicolumn{1}{|c|}{ ПОКАЗАТЕЛИ } & Коэффициенты & Т & Значимость \\
\hline (Константа) & 17,776 & 3,201 & 0,003 \\
\hline Образование & $-7,607$ & $-3,872$ & 0,000 \\
\hline Дополнение предложения & 1,158 & 2,849 & 0,007 \\
\hline
\end{tabular}

Рассматриваемые предикторы объясняют 26,7\% $\left(\boldsymbol{R}^{2}=\mathbf{0}, \mathbf{2 6 7}\right)$ дисперсии переменной «агрессивный тип реагирования». Таким образом, низкий уровень образования совместно с высокой осведомленностью приводит к тому, что человек чаще прибегает к агрессивной стратегии реагирования. Можно предположить, что высокая осведомленность побуждает респондентов к жесткости в отстаивании своей позиции. У таких респондентов создается иллюзия развитого интеллекта и, как следствие, сложность в интерпретации чужой точки зрения.

В таблице 2 представлены результаты регрессионного анализа, влияния вербального интеллекта, психологических особенностей личности и образования на тип реагирования «Уход» у участников форумов. Регрессионный анализ показал отрицательное влияние макиавеллизма на тип реагирования «Уход».

Таблица 2.

Результаты исследования влияния вербального интеллекта, психологических особенностей личности и образования на тип реагирования «Уход» участников форумов методом многофакторного регрессионного анализа.

\begin{tabular}{|l|c|c|c|}
\hline \multicolumn{1}{|c|}{ ПОКАЗАТЕЛИ } & Коэффициенты & т & Значимость \\
\hline (Константа) & 29,000 & 11,628 & 0,000 \\
\hline Макиавеллизм & $-0,380$ & $-3,544$ & 0,001 \\
\hline
\end{tabular}

Полученные результаты свидетельствуют о значительном вкладе в формировании типа реагирования данного фактора $\left(22 \%, R^{2}=0,267\right)$, однако так же можно наблюдать, что были учтены не все предикторы.

Корреляционный анализ типичной реакции «уход» показал отрицательную связь с субтестом на вербальный интеллект, который выявляет общую осведомленность ( $r=-0.315$ при $p=0.033)$. Представители с низкой осведомленностью видят себя неспособными отстаивать свою точку зрения, и предпочитают уход из конфликтной ситуации. Результаты в таблице 3.

Таблица 3. Достоверные корреляции показателя «Уход», особенности личности, вербального интеллекта участников форумов.

\begin{tabular}{|c|c|c|c|}
\multirow{2}{*}{$№$} & \multirow{2}{*}{ Личностные особенности } & \multicolumn{2}{|c|}{ Уход (избегание) (тип реагирования) } \\
\cline { 3 - 4 } & & $\mathrm{r}$ & $\mathrm{p}$ \\
\hline 1 & \multirow{2}{*}{ «Дополни предложение» } & $-0,315$ & 0,033 \\
\hline
\end{tabular}

Статистически значимые взаимосвязи были выявлены при исследовании неклинической психопатии, личностными особенностями, типами реагирования и вербального интеллекта (таблица 4). Были выявлены отрицательные корреляции между «психопатией» и ре- 
акцией «уход» $(r=-0,303$ при $\mathrm{p}=0,040)$, субтестом №3 на вербальный интеллект, который определяет уровень развития словесно-логического мышления ( $r=-0,481$ при $\mathrm{p}=0,001)$.

Таблица 4.

Достоверные корреляции показателя «Психопатия» и типами реагирования в конфликте и вербальным интеллектом участников форумов.

\begin{tabular}{|r|c|c|c|}
\multirow{2}{*}{$№$} & \multirow{2}{*}{ Личностные особенности } & \multicolumn{2}{|c|}{ Психопатия } \\
\cline { 3 - 4 } & & $r$ & $p$ \\
\hline 1 & Уход (избегание) & $-0,303$ & 0,040 \\
\hline 2 & «Аналогии» & $-0,481$ & 0,001 \\
\hline
\end{tabular}

Данные можно интерпретировать следующим образом: людям с высокой выраженностью психопатии, т.е. тем, кто условно имеет низкий уровень или отсутствие эмпатии и отсутствие угрызения совести, не свойственно реагировать на сложные ситуации избеганием или уходом от проблем. Это можно объяснить тем, что люди компенсируют дефицит в эмоциональной сфере и проявляют интерес к различным конфликтам. Так же надо отметить, что эти люди имеют низкий уровень по шкале «аналогии» в тесте по выявлению уровня вербального интеллекта. По этой шкале определяется уровень словесно-логического мышления. Другими словами, испытуемые имеющие высокие показатели по психопатии имеют сложности логически выстраивать свои мысли и проблемы с грамотным использованием языка. Можно предположить о том, что так как у таких людей низкий уровень эмпатии, т.е. способность понимать переживания другого человека, то это влияет на формирование словесно-логического мышления.

Респонденты, которые предпочитают использовать стратегию «уход» имеют низкие показатели шкалы общей осведомленности в самых разных областях, этот показатель необходим для мыслительной деятельности [Ясюкова]. Можно предположить, что человеку с низкой осведомленностью сложно выстраивать коммуникативные связи с оппонентами и отстаивать свою точку зрения, а избегание является, по мнению данных респондентов, наиболее выигрышной стратегией. Участники форумов склонные к избеганию конфликта, имеют низкие показатели по шкале макиавеллизм, т. е. тем людям, склонным к обманам, манипулированию, не свойственно уходить из ситуации, т. к. в этом случае они теряют контроль над ситуацией. Так же, избегая конфликты, люди пытаются уйти от негативных эмоций, что, видимо, не свойственно участникам форумов с высокими показателями психопатии.

По аналогии была разобрана типичная реакция реагирования - «решение», в таблице 5 представлены результаты регрессионного анализа.
Таблица 5.

Результаты исследования влияния вербального интеллекта и психологических особенностей личности на тип реагирования «Решение» участников форумов методом многофакторного регрессионного анализа.

\begin{tabular}{|c|c|c|c|}
\hline ПОКАЗАТЕЛИ & Коэффициенты & т & Значимость \\
\hline (Константа) & 7,899 & 1,917 & 0,052 \\
\hline Макиавеллизм & 0,345 & 3,373 & 0,002 \\
\hline "Аналогии" & 0,554 & 2,388 & 0,021 \\
\hline
\end{tabular}

Полученные данные свидетельствуют что на 24,6\% $\left(R^{2}=0,246\right)$ предикторы «макиавеллизм» и «аналогии» влияют на формирование типа реагирования «Решение». Чем выше данные респондентов по шкале «макиавеллизм» и «аналогии», выявляющий уровень развития словесно-логического мышления, т. е. это форма мыслительной деятельности, при которой человек с помощью речи выражает логические умозаключения и имеет способность аргументировать свои мысли, тем более выражен тип реагирования «решение».

Можно предположить, что способность анализировать и формировать сложные интеллектуальные модели, собирать объемный образ и интегрировать чужие взгляды в него, позволяет в конфликтной ситуации участнику форумов пытаться решить трудную ситуацию.

В таблице 6 представлен корреляционный анализ с типом реагирования «решение» с личностными особенностями. При анализе типичной реакции «решение», данные демонстрируют положительную корреляцию с субтестом на вербальный интеллект, который выявляет общую осведомленность ( $r=0,330$ при $p=0,025)$, с уровнем вербального интеллекта ( $r=0,311$ при 0,035), с «образованием» $(r=0,311$ при $p=0,035)$.

Таблица 6.

Достоверные корреляции показателя «Решение», особенности личности, вербального интеллекта участников форумов.

\begin{tabular}{|c|c|c|c|}
\multirow{2}{*}{ № } & \multirow{2}{*}{ Личностные особенности } & \multicolumn{2}{|c|}{ Решение (тип реагирования) } \\
\cline { 3 - 4 } & & $\mathrm{r}$ & $\mathrm{p}$ \\
\hline 2 & «Дополни предложение» & 0,33 & 0,025 \\
\hline 2 & $\begin{array}{c}\text { Сумма (вербальный } \\
\text { интеллект) }\end{array}$ & 0,311 & 0,035 \\
\hline 3 & образование & 0,311 & 0,035 \\
\hline
\end{tabular}

Таким образом, полученные данные свидетельствуют о том, что люди, которые в конфликтных ситуациях ищут способы решить проблему обладают развитым вербальным интеллектом, хорошо осведомлены и имеют высшее образование, т.е. имеют те факторы, которые позволяют формировать сложную интеллектуальную модель благо- 
даря которой могут рассматривать ситуацию с разных сторон.

Анализируя полученные данные, можно сделать следующие выводы. В работе доказано влияние вербального интеллекта, психологических особенностей на типы реагирования в конфликте участников форумов. На агрессивный тип реагирования положительно влияет общая осведомлённость и отрицательно влияет уровень образования. Тип реагирования «уход» отрицательно взаимосвязан с неклинической психопатией и с общей осведомленностью. Так же, можно наблюдать отрицательное влияние макиавеллизма на данный тип реагирования. При типе реагирования «решение» выявлена положительная взаимосвязь с общей осведомленностью, уровнем вербального интеллекта, уровнем образования. Выявлено положительное влияние макиавеллизма и уровня развития словесно-логического мышления. Можно наблюдать, что такие факторы, как уровень образования, уровень вербального интеллекта и общая осведомленность взаимосвязаны с данной стратегией реагирования.

\section{ЛИТЕРАТУРА}

1. Бандура А. Уолтерс Р. Подростковая агрессия. - М., Апрель Пресс, Изд-во ЭКСМО-Пресс, 1999. - 512с.

2. Витгенштейн Л. - Логико-философский трактат. - Москва: АСТ, - 2018. - С. 160.

3. Выготский Л.С. Мышление и речь. - СПБ.: Питер, 2017. - С. 432

4. Голев Н.Д. - Русская письменная разговорная речь и ее отражение в обыденном метаязыковом сознании участников виртуальной коммуникации Вестник Томского государственного университета. Филология. 2013. №5. - С. 12-30.

5. Доценко, Е.Л. - Психология манипуляции: феномены, защита и механизмы - М.: Издательство ЮРАЙТ, 2000 - С. 344

6. Курпатов А.В. Мышление. Системное исследование - М.: Капитал, 2018. - 672с.

7. Черниговская Т.В. Чеширская улыбка кота Шрёдингера. Язык и сознание. - Языки славянских культур, 2016. - С. 448

8. Шейнов В.П. - Взаимосвязи виктимизации, макиавеллизма и поведения в конфликте - Вестник Российского университета дружбы народов, серия: психология и педагогика, $2018-$ С. 431-445

9. К Кэтин л. Колдуэлл-Харрис, Scientific American 15 января 2019 года https://www.scientificamerican.com/article/our-language-affects-what-we-see/ (дата обращения: 20.01.2020).

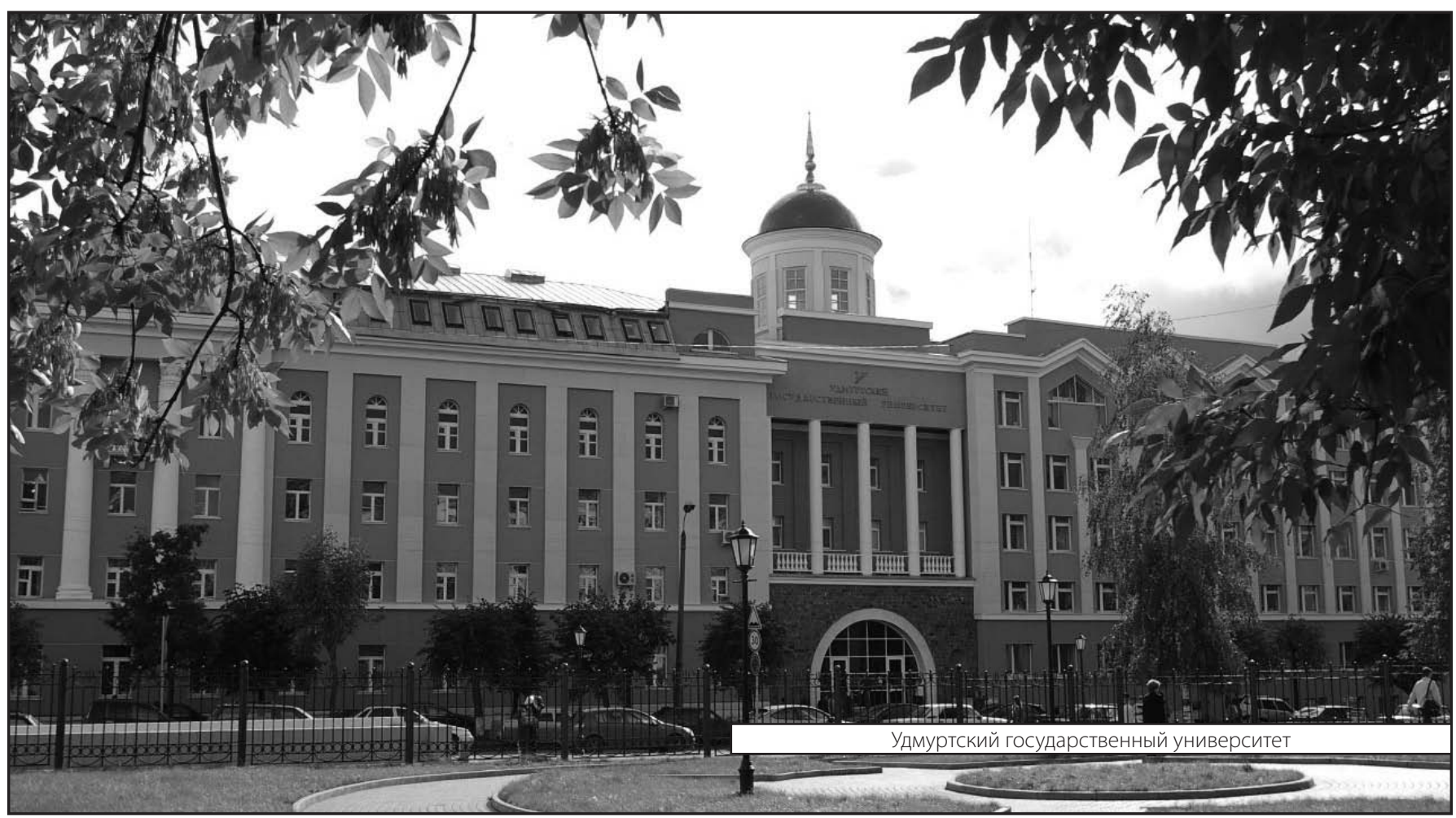

